\title{
Malaria and Helminth Coinfection among Children at the Douala Gyneco-Obstetric and Pediatric Hospital
}

\author{
Ashungafack Flavio $\mathbb{D}^{1},{ }^{1}$ Yamssi Cedric $\left(\mathbb{D},{ }^{2}\right.$ Noumedem Anangmo Christelle Nadia $\mathbb{D}^{3},^{3}$ \\ and Vincent Khan Payne ${ }^{1}{ }^{1}$ \\ ${ }^{1}$ Department of Animal Biology, Faculty of Science, University of Dschang, P. O. Box 067, Dschang, Cameroon \\ ${ }^{2}$ Department of Biomedical Sciences, Faculty of Health Sciences, University of Bamenda, P. O. Box 39, Bambili, Cameroon \\ ${ }^{3}$ Department of Microbiology, Hematology and Immunology Faculty of Medicine and Pharmaceutical Sciences, \\ University of Dschang, P. O. Box 96, Dschang, Cameroon
}

Correspondence should be addressed to Yamssi Cedric; cyamssi@yahoo.com and Vincent Khan Payne; vk.payne@yahoo.com

Received 8 April 2021; Accepted 24 June 2021; Published 1 July 2021

Academic Editor: Pedro P. Chieffi

Copyright (c) 2021 Ashungafack Flavio et al. This is an open access article distributed under the Creative Commons Attribution License, which permits unrestricted use, distribution, and reproduction in any medium, provided the original work is properly cited.

\begin{abstract}
Background. Malaria and helminth infections are major public health issues in sub-Saharan Africa including Cameroon. This study was aimed at determining the prevalence and risk factors associated with malaria and helminth coinfection among children in the Douala Gyneco-Obstetric and Pediatric Hospital (HGOPED) in Douala, southwestern Cameroon. Material and Methods. The study was a hospital-based cross-sectional study that took place from January to July 2020 where 203 children were involved. Blood samples were collected from the children and thick blood smears were prepared and examined microscopically for malaria parasites. Stool samples were also collected and examined through the Kato-Katz technique for the identification of helminth eggs. Demographic and socioeconomic data and information of participant's knowledge on the transmission of malaria and helminth infections were collected with the use of a well-structured questionnaire. Results. The overall prevalence of $P$. falciparum infection was $28.8 \%$, while the overall prevalence of helminth was $9.36 \%$. The only species of helminth identified were Ascaris lumbricoides and Trichuris trichiura with a prevalence of $4.26 \%$ and $2.95 \%$, respectively, and mixed infection of both A. lumbricoides and T. trichiura with a prevalence of $1.47 \%$. Coinfection of malaria and helminth was observed with a prevalence of $6.90 \%$. Associations of malaria-helminth coinfection with age groups, parent's educational level, type of latrine, and source of water factors were not statistically significant ( $p>0.05$ ), while the prevalence of the coinfection with respect to parent's occupation, presence of stagnant water around homes, washing of hands after using the toilet, and washing of fruits before eating was statistically significant $(p<0.05)$. Conclusion. The findings suggest that helminths and malaria infections tend to occur in children. Not washing hands after using the toilet, not washing fruits before eating, the presence of stagnant water around homes, and parents' occupation were found to be strongly associated with coinfection. Health education on the importance of better sewage disposal, draining of stagnant water around homes, and other sanitary practices is recommended.
\end{abstract}

\section{Introduction}

It is estimated that over a third of the world's population, mainly living in the tropics and subtropics, are infected by at least one intestinal helminth (worm) or a protozoan parasite species $[1,2]$ which, according to Degarege et al. [3], may adversely impact the outcome of the disease they cause.

Malaria is a febrile illness caused by an infectious parasitic protozoan of the genus Plasmodium through the bite of an infected female Anopheles mosquito [4]. Though it is caused by several Plasmodium protozoan parasites, Plasmodium falciparum is the most dangerous. Malaria is widespread in tropical and subtropical parts of America, Asia, and Africa. Each year, there are more than 250 million cases of malaria, killing between 1 and 3 billion people, the majority of whom are young children in sub-Saharan Africa [2]. Of all human diseases caused by protozoan parasites, malaria has the greatest burden and is responsible for the 
highest number of deaths among young children in subSaharan Africa, accounting for $90 \%$ of all global cases [5].

In addition to malaria, other parasitic diseases are common among the world's poorest people. According to Hotez and David [5], there are about 13 parasitic infections that are responsible for significant morbidity but have not gotten the attention they deserve; thus, they are now known as "Neglected Tropical Diseases" (NTDs). Three of these are soil-transmitted helminthic infections (STH) (Ascaris lumbricoides), whipworm (Trichuris trichiura), and hookworm (Ancylostoma duodenale and Necator americanus). They are so-called soil-transmitted helminths because their infection on man is transmitted via contaminated soil by parasitic invasive eggs or larvae.

In Cameroon, both malaria and helminth infections coexist and are ranked among the major causes of parasitic mortality and morbidity with Plasmodium falciparum being the most prevalent and virulent species of malaria parasite [6-8]. The prevalent and ubiquitous geohelminths A. lumbricoides, T. trichiura, A. duodenale, and Strongyloides stercoralis are the major helminth species [9-11]. This frustrates the health achievements in the millennium development goals and impedes public health outcomes [12].

This study aims to determine the prevalence and risk factors associated with malaria and helminth coinfection among children in the Douala Gyneco-Obstetric and Pediatric Hospital to contribute to the existing data on coinfection of malaria and helminth in Cameroon, making recommendations for further regional and nationwide control programs.

\section{Materials and Methods}

2.1. Study Site. The study was conducted in the Douala Gyneco-Obstetric and Pediatric Hospital (HGOPED). Douala, which is the largest city of Cameroon, is found in the littoral region of the country with around 2.5 million inhabitants. It is located at latitude $4^{\circ} 3^{\prime} 41.5296^{\prime \prime} \mathrm{N}$ and longitude $9^{\circ} 47^{\prime} 9.8592$ " $\mathrm{E}$ within the Congo-Guinean phytogeographic zone near the Atlantic coast and lies about one meter above sea level.

2.2. Study Design and Sample Size. This study was a hospitalbased cross-sectional study. The study population was made up of children (1 to 16 years old) of both sexes (male and female) present at the Douala Gyneco-Obstetric and Pediatric Hospital whose written and signed parental/guardian consent was obtained for participation in the study. The sample size was be determined using Lorenze's formula:

$$
n=\frac{z^{2} p q}{d^{2}}
$$

where $n=$ required sample size, $Z=$ confidence interval at 95\% (standard value $=1.96$ ),$P=$ estimated prevalence, $q$ $(1-p)=$ expected nonprevalence, and $d=$ margin of error at $5 \%$ (0.05) or maximum tolerable error.

The estimated prevalence of $22.1 \%$ (0.0221) was used:

$$
n=\frac{(1,96)^{2}(0,0221)(0,929)}{(0,05)^{2}}=264.5 .
$$

It is approximately 265 subjects.

2.2.1. Inclusion Criteria. All children from 1 to 16 whose parents/guardians accepted to give his/her consent were included.

2.2.2. Exclusion Criteria. Children whose parents/guardians refused to give his/her consent were immediately excluded.

2.3. Administration of Questionnaire. In order to collect primary data, all consented participants assisted by their parents/guardians were given a well-structured questionnaire designed to collect personal and sociodemographic information such as age and sex of the pupil, characteristics of their homes, and their knowledge on the transmission of malaria and soil-transmitted helminth infections.

2.4. Collection of Stool Samples. Well labelled sterile containers with individual identification number were distributed to all participants who were instructed on how to do a proper fresh fecal sample collection. The stool samples collected were taken to the laboratory and examined immediately.

2.5. Laboratory Analysis of Stool and Blood Samples Collection. Parasitological examination of stool sample was done using the Kato-Katz technique [12]. After sterilizing the fingertip, a drop of blood was collected by finger prick and thick blood smears were prepared for malaria parasite identification and examined under the microscope at a 10x objective.

2.6. Data Analysis. Data collected and stored in a computer using Microsoft Excel 2013 was transferred to XLSTAT. Data obtained was analyzed using descriptive statistics where variables were summarized using frequencies and percentages. Chi square test was used to test for the association between malaria and helminth coinfection and its related risk factors and Pearson correlation was used to test the strength of the association between variables. The statistical significance threshold was set at $p<0.05$.

\section{Results}

Table 1 shows the prevalence of malaria and helminth infection. It follows from the analysis of this table that 57 (28.08\%) of the patients were positive for malaria parasite, 24 (42.10\%) males and 33 (57.89\%) females. It also shows that $19(9.36 \%)$ of the participants had soil-transmitted helminth infection. Of these 19, 11 (4.95\%) had A. lumbricoides infections, $6(2.95 \%)$ had $T$. trichiura infection, and 3 (1.47\%) had both A. lumbricoides and T. trichiura.

Table 2 shows the prevalence of malaria and helminth coinfection. It appears from this table that, out of 203 
TABLE 1: Prevalence of malaria and helminth infection and parasitic associations

\begin{tabular}{lc}
\hline Variable & Frequency (\%) \\
\hline Malaria status & $\mathbf{5 7}(\mathbf{2 8 . 0 8 )}$ \\
$\quad$ Positive $(\mathbf{n}=\mathbf{5 7})$ & $24(42.10)$ \\
$\quad$ Male & $33(57.89)$ \\
$\quad$ Female & $\mathbf{1 4 6}(\mathbf{7 1 . 9 3})$ \\
Negative (146) & $74(50.68)$ \\
$\quad$ Male & $72(49.32)$ \\
$\quad$ Female & $\mathbf{1 9}(\mathbf{9 . 3 6 )}$ \\
Helminth infection $(\mathbf{n}=\mathbf{1 9 )}$ & $10(4.26)$ \\
Ascaris lumbricoides & $6(2.95)$ \\
Trichuris trichiura & $3(1.47)$ \\
Ascaris lumbricoides/Trichuris trichiura & \\
\hline
\end{tabular}

TABLE 2: Prevalence of malaria-helminth coinfection.

\begin{tabular}{lccc}
\hline & Positive & Negative & Coinfection \\
\hline Malaria & $43(28.08)$ & $146(71.92 \%)$ & $14(6.90 \%)$ \\
Helminth & $5(2.46 \%)$ & $184(90.64 \%)$ & 14 \\
\hline
\end{tabular}

Risk factors associated with malaria-helminth coinfection.

participants, $14(6.90 \%)$ had malaria and soil-transmitted helminth coinfection, $5(2.46 \%)$ had soil-transmitted helminth infection, and 43 (21.187\%) had malaria infection.

From the $p$ values and Pearson correlation values presented on Table 3, it appears that washing hands after using the toilet was significantly associated with malaria-helminth coinfection $(p=0.001)$. It also reveals that washing fruits before eating and patients' behavior of "sometimes" washing their fruits before eating were significantly associated with malaria-helminth coinfection $(p=0.001)$; equally the presence of stagnant water and unemptied bottles around patient were significantly associated with coinfection $(p=0.001)$. Parents" economic status of having "no job" was strongly associated with coinfection $(p=0.043)$.

\section{Discussion}

This study shows an overall malaria prevalence of $28.8 \%$ which is slightly similar to $33 \%$ observed by Laurantine et al. [12] in Tombel health district. This similarity in the observed prevalence may be due to similarity in climatic conditions responsible for the development of malaria vector in these two regions. This observed prevalence however differs from $45.47 \%$ malaria prevalence obtained by Leopold et al. [13] from their study on the epidemiology of malaria among school children in Douala. This may be explained by the fact that though their study population was on children as in this study, it only included children of 3 to 16 years; meanwhile this study includes children of 1 to 16 years. Also, their study design was school-based while our study was hospital-based.

The overall prevalence of STH registered in this study was $8.87 \%$ which is lower compared to that observed in a similar study conducted by Zeukeng et al. [11] in the Mfou health district of the central region. This may be explained by the fact that Mfou district is in a rural area while HGOPED where this study was conducted is in an urban center with more access to pipe-borne water, hence lower chances of transmission by water contamination. Again, the study in Mfou district was conducted only in rural communities where farming and animal rearing are often the major occupations in rural areas; this increases the chances of soiltransmitted helminth. Also, no cases of hookworm infection were identified in this study; this confirms the result of studies conducted by Makoge et al. [14] in Mbonge and Tchinda et al. [7] in Mfou health district but disagrees with the study of Pone et al. [15] in Dschang and Degarege et al. [3]. The absence of hookworm may be associated with the type of soil in the area which may not be favorable for larval development. It may also be due to the time between stool processing and microscopy since hookworms start to degenerate after about 45 minutes of Kato-Katz preparation.

The overall prevalence of malaria-helminth coinfection obtained from this study was $6.8 \%$ which was similar to $7.1 \%$ prevalence obtained by Laurantine et al. [12] on a similar study in Tombel health district. This similarity in prevalence may be due to the similarity in the climatic conditions of the study area. It however differs from the prevalence of $22.1 \%$ observed by Zeukeng et al. [11] in Mfou health district of the central region. This may likely be because the study of Zeukeng was centered on all age groups, in the rural areas and with a large sample size; meanwhile, this study was only centered on children of age 1-16 years in HGOPED which is in an urban area and only 203 children were sampled.

There was a higher prevalence $(51.14 \%)$ of malariahelminth coinfection in children less than 5 years of age than in other age groups. This differs from the report of Zeukeng et al. [11] in Mfou health district where they reported a high prevalence of coinfection of malaria and helminth only in children between 5 and 11 years. But the high prevalence of coinfection among children less than 5 is not surprising because children at this age have not yet acquired strong immunity against malaria and they still have the habit of crawling and eating the soil which may be contaminated with helminth eggs. 
TABLE 3: Risk factors associated with malaria-helminth coinfection.

\begin{tabular}{|c|c|c|c|c|}
\hline \multirow{2}{*}{ Variable } & \multicolumn{2}{|c|}{ Coinfection } & \multirow{2}{*}{ Pearson correlation } & \multirow{2}{*}{$p$ value } \\
\hline & Positive $(n=14)$ & Negative $(n=189)$ & & \\
\hline \multicolumn{5}{|l|}{$\operatorname{Sex}$} \\
\hline Male & $6(42.56 \%)$ & $90(47.62 \%)$ & 0.048 & 0.498 \\
\hline Female & $8(57.14 \%)$ & $99(52.88 \%)$ & 0.048 & 0.494 \\
\hline \multicolumn{5}{|l|}{ Age group } \\
\hline$<5$ & $8(51.14 \%)$ & $76(40.21 \%)$ & 0.087 & 0.51 \\
\hline 5to 9 & $2(14.28 \%)$ & $90(47.61 \%)$ & 0.074 & 0.387 \\
\hline 10 to 16 & $4(28.57 \%)$ & $23(11.11 \%)$ & 0.021 & 1.00 \\
\hline Parent/guardian educational level & & & 0.085 & 0.225 \\
\hline Non & $0 \%$ & $20(10.58 \%)$ & 0.090 & 0.263 \\
\hline Primary & $3(21.43 \%)$ & $51(26.98 \%)$ & 0.032 & 0.665 \\
\hline Secondary & $8(51.14 \%)$ & $83(43.92 \%)$ & 0.067 & 0.855 \\
\hline Tertiary & $3(21.43 \%)$ & $3(21.43 \%)$ & 0.019 & 1.00 \\
\hline Parent occupation & & & 0.147 & 0.036 \\
\hline Casual & $3(21.43 \%)$ & $38(20.11 \%)$ & 0.008 & 0.306 \\
\hline Civil servant & $0(0 \%)$ & $20(10.58 \%)$ & 0.090 & 0.055 \\
\hline Self-employed & $8(57.14 \%)$ & $75(39.68 \%)$ & 0.0150 & 1.00 \\
\hline No job & $3(21.43 \%)$ & $56(29.63 \%)$ & 0.095 & 0.043 \\
\hline \multicolumn{5}{|l|}{ Habitat type } \\
\hline Cemented & $198(97.33 \%)$ & $185(97.88 \%)$ & 0.082 & 0.80 \\
\hline Plank & $4(1.97 \%)$ & $3(1.58 \%)$ & 0.101 & 0.38 \\
\hline Others & $1(0.493 \%)$ & $1(0.53 \%)$ & 0.019 & 1.00 \\
\hline Water source & & & 0.007 & 0.916 \\
\hline Borehole & $9(64.29 \%)$ & $114(76.19 \%)$ & 0.021 & 0.773 \\
\hline Pipe-borne & $5(35.71 \%)$ & $54(28.57 \%)$ & 0.189 & 0.107 \\
\hline Other sources & 0 & $21(11.11 \%)$ & 0.092 & 1.00 \\
\hline Toilet facility & & & 0.049 & 0.483 \\
\hline Water closet & $9(64.29 \%)$ & $137(72.49 \%)$ & 0.047 & 0.48 \\
\hline Pit latrine & $5(35.71 \%)$ & $51(26.98 \%)$ & 0.049 & 0.48 \\
\hline Washing hands after using the toilet & & & 0.297 & 0.0001 \\
\hline Yes & $3(21.43 \%)$ & $48(25.40 \%)$ & 0.297 & \\
\hline No & 0 & 0 & -- & \\
\hline Sometimes & $11(78.57 \%)$ & $141(74.60 \%)$ & 0.297 & \\
\hline Washing of fruits before eating & & & 0.274 & 0.0001 \\
\hline Yes & $4(28.57 \%)$ & $144(76.19 \%)$ & 0.019 & 0.000 \\
\hline No & 0 & 0 & 0.276 & 0.913 \\
\hline Sometimes & $10(71.43 \%)$ & $44(81.48 \%)$ & 0.271 & 0.000 \\
\hline Stagnant water pools around homes & & & & 0.0001 \\
\hline Yes & $12(85.71 \%)$ & $122(64.55 \%)$ & & \\
\hline No & $2(14.29 \%)$ & $67(34.44 \%)$ & 0.261 & \\
\hline
\end{tabular}

Based on the parent's occupation, a high prevalence of coinfection of $8(87.14)$ was recorded in children whose parents were self-employed ( $p=0.036$ ), followed by no job and casual workers compared with no case of coinfection observed in children of civil servants. This may be explained by the fact that parents with no job, casual workers, and selfemployed ones have low household income leading to poor feeding habits and consequently coinfection. This observation agrees with a previous study conducted by Lanne [16] in Sierra Leon where he reported that low family income of less than 50 USD was statistically more associated with malariahelminth coinfection in children.

It was also observed that poor sanitary practices such as not washing hands after using the toilet, not washing fruits before eating $(p=0.001)$, and the presence of stagnant water pools around homes were strongly associated with malaria- helminth coinfection. This agrees with the previous studies conducted by Nkuo-Akenji et al. [6] in the Southwest Region of Cameroon and Messina et al. [17] in Congo where they reported that environmental factors like stagnant water, bushes around homes, unhygienic conditions, and high temperatures favor the growth and transmission of both malaria and soil-transmitted helminth. This is not surprising because unwashed hands and fruits contain dust contaminated with eggs of helminth and meanwhile stagnant water pools serve as breeding grounds for Anopheles mosquitos, hence making coinfection inevitable.

\section{Conclusion}

The study reveals that there is coinfection of malaria and helminth among children in the Douala Gyneco-Obstetric 
and Pediatric Hospital. Poor hygiene practices such as not or "sometimes" washing hands after using the toilet, not washing fruits before eating, poverty resulting from parents having no job, and the presence of stagnant water pools around homes are significantly associated with malariahelminth coinfection among children in the Douala GynecoObstetric and Pediatric Hospital.

\section{Data Availability}

Data and material are available upon request to the corresponding author.

\section{Ethical Approval}

Before starting the study properly, the research proposal was submitted to the Douala Gyneco-Obstetric and Pediatric Hospital. Review Board (RHB) with Registration No. 39/ APP/DGOPH/RHB was contacted for evaluation and request for ethical clearance which was approved.

\section{Conflicts of Interest}

The authors declare that they have no conflicts of interest.

\section{Authors' Contributions}

AF, VKP, YC, and NACN contributed to the design of the study and data collection and led the analysis and drafting of the manuscript. All authors read and approved the final manuscript.

\section{Acknowledgments}

The authors are sincerely grateful to research unit of Applied Biology and Ecology.

\section{References}

[1] N. R. De Silva, S. Brooker, P. J. Hotez, A. Montresor, D. Engels, and L. Savioli, "Soil-transmitted helminth infections: updating the global picture," Trends in Parasitology, vol. 19, no. 12, pp. 547-551, 2003.

[2] R. W. Snow, C. A. Guerra, A. M. Noor, H. Y. Myint, S. I. Hay, and S. Hay, "The global distribution of clinical episodes of Plasmodium falciparum malaria," Nature, vol. 434, no. 7030, pp. 214-217, 2005.

[3] A. Degarege, L. Mengistu, M. Girmy, A. Abebe, and E. Berhanu, "Malaria and related outcomes in patients with intsestinal Helminths: a cross sectional study," BMC Infectious Diseases, vol. 12, pp. 1471-2334, 2012.

[4] E. G. Francis, "History of the discovery of malaria parasite and their vectos," Parasite and Vectors, vol. 3, no. 1, pp. 2-9, 2010.

[5] P. J. Hotez and H. David, "Tropical anemia: one of the Africa's Great killer and a rational for linking malaria and neglected tropical disease control to achieve a common goal," PloS Neglected Tropical Disease, vol. 3, no. 8, pp. 1018-1027, 2009.

[6] T. Nkuo-Akenji, N. N. Ntonifor, M. B. Ndukum, E. L. Abongwa, and A. Nkwescheu, "Environmental factors affecting malaria parasite prevalence in rural Bolifamba, South West Cameroon," African Journal of Health Science, vol. 13, pp. 40-46, 2006.
[7] M. Tchinda, R. Ponka, S. Ndzi, K. Madocgne, and A. Motsebo, "Prevalence of malaria and soil-transmitted helminth infections and their association with undernutrition in schoolchildren residing in Mfou health district in Cameroon," Journal of Public Health and Epidemiology, vol. 4, no. 9, pp. 253-260, 2012.

[8] L.-A. Tchuem Tchuenté, J. M. Behnke, F. S. Gilbert, V. R. Southgate, and J. Vercruysse, "Polyparasitism with Schistosoma haematobium and soil-transmitted helminth infections among school children in Loum, Cameroon," Tropical Medicine \& International Health, vol. 8, no. 11, pp. 975-986, 2003.

[9] L. Nkengazong, F. Njiokou, S. Wanji, F. Teukeng, and P. Enyong, "Prevalence of soil transmitted and impact of Albendazole on parasitic indices in kotto Barombi and Marumba II villages (south-west Cameroon)," Africa Journal of Environmental Science and Technology, vol. 4, no. 3, p. 115, 2010.

[10] E. Lum, N. Kimbi, J. Mbuh, N. Ndamukon, and A. Njunda, "Co-infection of malaria and soil transmitted helminth in localities with different level of urbanization in Mount Cameroon," Jounal of Parasitology and Bacteriology, vol. 3, no. 2, pp. 2155-9597, 2012.

[11] F. Zeukeng, M. Vivian, D. B. Jude et al., "Co-infection of malaria and geohelminth in two rural communities of Nkassomo and Vian in the Mfou Health district," Plos Neglected Tropical Diseases, vol. 8, no. 1, p. 1371, 2010.

[12] M. N. Laurantine, W. Samuel, P. Winston et al., "An assessment of the endemicity of Plasmodium falciparum and soil transmitted helminth infections in the Tombel Health District of Cameroon: implications for monitoring the progress of disease control programs," International Journal of Healthcare Science, vol. 6, no. 1, pp. 375-383, 2018.

[13] G. L. Léopold, P. K. Loick, T. Calvin et al., "Epidemiology of malaria using LED fluorescence microscopy among schoolchildren in Douala, Cameroon," International Journal of Tropical Disease \& Health, vol. 29, no. 1, pp. 1-13, 2018.

[14] V. Makoge, G. Mbah, L. Nkengazong, N. Ndzi Edward Sahfe, and R. Moyou, "Falciparum malaria, helminth infection, and anaemia in asymptomatic pupils in four villages in Cameroon," European Journal of Zoological Research, vol. 1, no. 2, pp. 54-59, 2012.

[15] J. Pone, P. E. Alango, M. Mbida, and C. Bilong, "Prevalence and intensity of infections of three neglected tropical diseases in patients consulted at a Traditional Health Care Centre in Dschang West Cameroon," Tropical Parasitology, vol. 2, no. 1, pp. 24-28, 2012.

[16] S. Kining'hi, P. Magnussen, and G. Kaatano, "Malaria and helminth coinfections in school and preschool children," PLoS One, vol. 9, no. 1, Article ID 86510, 2014.

[17] J. P. Messina, S. M. Taylor, S. R. Meshnick et al., "Population, behavioural and environmental drivers of malaria prevalence in the Democratic Republic of Congo," Malaria Journal, vol. 10, no. 1, p. 161, 2011. 